\title{
Dissimilarities in Attitudes between Students in Service and Mainstream Courses towards Statistics: An Analysis Conducted in a Developing Country
}

\author{
Vaughan van Appel ${ }^{1 *}$, Rina Durandt ${ }^{1}$ \\ ${ }^{1}$ University of Johannesburg, Auckland Park, SOUTH AFRICA
}

Received 24 January 2018 - Revised 25 April 2018 - Accepted 1 May 2018

\begin{abstract}
In this study, we firstly investigate the attitudinal differences towards statistics between students (from a developing country) in service module and mainstream courses; and, secondly, differences in their attitudes over time, at the beginning and at the end of these courses. Knowledge regarding descriptive and inferential statistics are required for students at tertiary level in many disciplines, and the literature confirms (especially in developing countries) the under-preparedness (at all year levels), inadequate performance and low motivation of students in such courses. An international acknowledged instrument (SATS-36) revealed students' (from different faculties) initial attitudes towards statistics on six components (affect, cognitive competence, value, difficulty, interest and effort) and statistical significant differences between pre- and post-test data. The main implication from these findings are that students (in all faculties) tend to decrease in attitudinal scores over time, and educators can take awareness of this when designing pedagogy in statistics modules.
\end{abstract}

Keywords: attitudes towards statistics and gender, learning statistics, student attitudes in mainstream statistic courses, student attitudes in service module statistic courses, teaching statistics

\section{CONTEXT AND PURPOSE}

Over the last two decades statistics education emerged worldwide as a discipline in its own right (Garfield \& BenZvi, 2007; Jose, 2017), although it is closely connected to mathematics education. Garfield and Ben-Zvi (2007) reviewed multiple studies (conducted by researchers globally over a variety of disciplines including students at all levels) focusing on the teaching and learning of statistics and probability. Through their investigation, they identified difficulties students have in learning statistics and suggested educators should revisit traditional teaching methods. Recently, Jose (2017) argued that researchers altogether should investigate different pathways (such as writing literature reports, conferences and workshops participation) to acquire innovative knowledge about methodology and statistics. Within the South African education system, the topics statistics and probability are initially introduced to students as a component of the mathematics school curriculum (CAPS) (Department of Basic Education, 2011). Furthermore, fundamental and progressive statistical knowledge that requires competencies such as representing data, calculating probability, the notion of distribution, variability, sampling and statistical inference, is required in a variety of courses over many faculties (science, engineering, business, humanities, education and others) at tertiary level. The students enrolled for these courses do not necessarily have a strong mathematical background. The unsatisfactory performance of students (particularly in developing countries) in mathematics at school is well documented and confirmed by international tests of educational achievement, such as TIMSS (Trends in International Mathematics and Science Study) (Juan \& Visser, 2017; Spaull, 2013), and similar trends are experienced at tertiary level (Rylands \& Coady, 2009). Juan and Visser (2017) collected data from almost twelve thousand Grade 9 South African students from different socio-economic environments and confirmed the influence of socio-economic factors on science achievement. Rylands and Coady (2009)

(c) 2018 by the authors; licensee Modestum Ltd., UK. This article is an open access article distributed under the terms and conditions of the Creative Commons Attribution License (http://creativecommons.org/licenses/by/4.0/). \vvanappel@uj.ac.za vvanappel@gmail.com (*Correspondence) $\square$ rdurandt@uj.ac.za 


\section{Contribution of this paper to the literature}

- Statistics students in service modules revealed lower attitudinal scores towards statistics than students in mainstream courses. However, all students decreased in attitudinal scores over time.

- Statistics students in different faculties should ideally be engaged in a well-planned set of activities, focusing on their particular professional development, aimed at strengthening their competencies and gradually improving their attitudes towards the subject.

- Some teaching and learning practices were identified from this investigation, which can be used by statistics educators from different disciplines to enhance statistical reasoning, thinking and literacy in students.

highlighted the importance of students' (from an Australian public university) strong mathematical secondary school background on their performance in science subjects at first-year tertiary level. Furthermore, research findings (Yousef, 2017) from data collected at a non-Western (Arabic) setting from 750 undergraduate business students, confirmed a selection of aspects play a role in students' understanding of quantitative course material, apart from their mathematical knowledge. Some of these aspects are the teaching style of the lecturer in relation to how the lecturer speaks, the pace and structure of presenting the content, the communication between lecturer and student, language of instruction, and the availability of course content via an electronic learning environment.

In addition, positive attitudes of students towards statistics could influence students' enrolment, achievement and motivation towards quantitative courses (Coetzee \& van der Merwe, 2010). Research results from Coetzee and van der Merwe (2010, p. 1), conducted in South Africa, revealed "the degree to which students perceived themselves to be competent in mathematics was related to the degree to which they felt confident in their own ability to master statistics". We were of the opinion that students from different faculties view and experience the learning of statistics courses (mainstream courses versus service module courses) differently; findings from Sulieman (2015), comparing 440 undergraduate students' (from the American University of Sharjah in the UAE) attitudinal differences across different majors, strengthened this opinion.

A mainstream statistics course is catering for students who major in statistics or in mathematical sciences, while a service module statistics course is catering for students whose majors falls outside the natural sciences, such as commerce, health sciences or engineering. Mainstream courses usually have a stronger theoretical base than service courses, although both focus on contextual applications and interpretations. Related to this study, both courses are offered by experienced lecturers, in statistical and pedagogical knowledge, and both courses consist of a similar layout (with a rather strong focus on assessment).

In this study, we explored the attitudes of students at a public university in South Africa, in the Faculty of Science (students enrolled for statistics as a mainstream course), the Faculty of Management and the Faculty of Engineering (students enrolled for statistics as a service module course). We expect students in mainstream statistics modules to have a more positive outlook towards statistics than students enrolled for service reasons.

The purpose of the study is to explore the initial attitudinal differences of students between mainstream and service course and to track these over time (from the beginning to the end of a course). The two research questions this inquiry attempts to answer are as follow:

- What are the initial differences between the attitudes of students in service and mainstream courses toward statistics?

- Are there changes in the attitudinal scores of statistics students (between mainstream and service courses) from the beginning (labelled as the pre-test) to the end of the particular module (labelled as the post-test)?

This inquiry can broaden our knowledge about how students in developing countries across disciplines experience statistics courses. It strives to identify some teaching and learning practices which can be used by statistics educators from different disciplines to enhance statistical reasoning, thinking and literacy in students and to improve their disposition towards the subject.

\section{LITERATURE PERSPECTIVES}

\section{Underlying Theoretical Framework}

We grounded our view on learning statistics so that students develop a conceptual understanding of the content, on the "Statistical Reasoning, Thinking, and Literacy" framework from Garfield and Ben-Zvi (2007, p. 380). According to this framework, there are clear distinctions between statistical literacy, reasoning and thinking. Although all three components are interconnected, and a type of hierarchy does exist, statistical literacy forms the foundation for reasoning and thinking. Garfield and Ben-Zvi (2007, pp. 380-381) explained Statistical Literacy (which is often the expected outcome of introductory courses in statistics) as an "understanding and using the basic 
language and tools of statistics: knowing what basic statistical terms mean, understanding the use of simple statistical symbols, and recognising and being able to interpret different representations of data", whereas Statistical Reasoning is "the way people reason with statistical ideas and make sense of statistical information", and Statistical Thinking "involves a higher order of thinking than statistical reasoning ... the way professional statisticians think". We are of the opinion all three components are important for students to develop a proficiency in statistics.

Garfield and Ben-Zvi (2007), supported by other literature sources (Bakker \& Gravemeijer, 2004; Chick \& Watson, 2002; Garfield \& Chance, 2000; Pfannkuch, 2005) in the field of statistics education and based on original work (proposed 10 principles) from Garfield (1995), introduced a list of eight principles about how students learn statistics. These research-based principles (Garfield \& Ben-Zvi, 2007, pp. 387-389), which provide insight to educators, are: (1) "students learn by constructing knowledge" (they enter the learning environment with prior knowledge and tend to accept new ideas only if their previous ideas do not work); (2) "students learn by active involvement in learning activities" (they tend to learn cooperatively when solving problems); (3) "students learn to do well only what they practice doing" (they tend to learn more efficiently when they experience applying new ideas); (4) "difficulty students have in understanding basic concepts of probability and statistics" can easily be underestimated, as well as an overestimation of; (5) "how well students understand basic concepts"; (6) "learning is enhanced by having students become aware of and confront their errors in reasoning" (they are often slow to change misconceptions); (7) "technological tools should be used to help students visualize and explore data, not just to follow algorithms to pre-determined ends" (these tools provide students opportunities to explore); and (8) "students learn better if they receive consistent and helpful feedback on their performance" (they require time to reflect on the feedback, make changes and attempt problems again).

Although these principles emerged from studies conducted globally, we are of the opinion these eight principles are applicable for the teaching and learning of statistics in a South African context. Related to this inquiry, the instruction of both mainstream and service courses is informed by strong educational research following the beforementioned notion from Jose (2017), but also considering the above-mentioned principles from Garfield and BenZvi (2007). It almost seems as if the course instructors are still searching for the best scenario to intertwine theory and practice for both mainstream and service courses.

\section{Literature Perspective on Attitudes}

An overview of the literature suggests a relation between learning statistics and a positive attitude towards the discipline. Coetzee and van der Merwe (2010) confirmed this and explained attitudes towards statistics as a multidimensional concept, focusing first on an affective domain such as emotions and motivation, second on a cognitive domain such as beliefs and knowledge about the discipline, and third on a behavioural domain with regards to tendencies in studying the content. We considered the theory on learning statistics and fostering a confident attitude towards statistics as equally important components.

\section{RESEARCH DESIGN}

\section{Research Paradigm}

This inquiry relates to an attempt to measure the attitudes of students' in mainstream and service courses towards statistics, conducted from a post-positivist worldview (Creswell, 2013). The term post-positivism refers to a thinking that does not focus on the reductionist views of positivism but, rather, implies an evidence-based, quantitative approach to research. From this viewpoint, we reflect a need to examine reasons that affect results. Such developed knowledge is based on measures, completed by participants, and reflect a real-world reality. Phillips and Burbules (2000) discussed some fundamental assumptions related to this paradigm. Two of these assumptions, relevant for this study are, firstly, the collection of data on an instrument to shape knowledge and, secondly, the attempt to explain a situation by studying the relationship between variables.

\section{Research Instrument}

Multiple surveys, measuring students' attitudes towards statistics, exists in the literature (see e.g. Nolan, Beran, \& Hecker, 2012). From these, a large interest in monitoring and assessing students' attitudes in statistics modules has developed, mostly with the aim to predict and improve performance. In this study, we selected an internationally acknowledged instrument, Survey of Attitude toward Statistics (SATS-36), based on two reasons. Firstly, it has been used both locally, (Coetzee \& van der Merwe, 2010) and internationally (Mills, 2004; Schau, Stevens, Dauphinee, \& Del Vecchio, 1995; Vanhoof, Kuppens, Sotos, Verschaffel, \& Onghena, 2011); and, secondly, the instrument comprises of a pre-test and a post-test. Schau et al. (1995) originally introduced SATS-28, consisting of 28 questions separated among four factors: affect (describing students' feelings concerning statistics); cognitive 
Table 1. Descriptive statistics of the pre-test participants

\begin{tabular}{llcc}
\hline Item & Category & Freq. & $\%$ \\
\hline \multirow{2}{*}{ Gender } & Female & 236 & 39.3 \\
\cline { 2 - 4 } If the choice had been yours, how likely is it & Male & 364 & 60.7 \\
\hline \multirow{2}{*}{ that you would have chosen to take statistics? } & Not at all likely & 155 & 25.8 \\
\cline { 2 - 4 } & Somewhat likely & 260 & 43.3 \\
\cline { 2 - 4 } & Very likely & 178 & 29.7 \\
\hline \multirow{2}{*}{ Home Language } & Afrikaans & 18 & 3.0 \\
\cline { 2 - 4 } & English & 115 & 19.2 \\
\cline { 2 - 4 } & Indigenous South African or African language & 442 & 73.7 \\
\cline { 2 - 4 } & Other (Chinese, French, etc.) & 24 & 4.1 \\
\hline
\end{tabular}

Table 2. Descriptive statistics of the post-test participants

\begin{tabular}{llcc}
\hline Item & Category & Freq. & $\%$ \\
\hline \multirow{2}{*}{ Gender } & Female & 182 & 50.3 \\
\cline { 2 - 4 } If the choice had been yours, how likely is it & Male & 180 & 49.7 \\
\cline { 2 - 4 } that you would have chosen to take statistics? & Not at all likely & 113 & 31.2 \\
\cline { 2 - 4 } & Somewhat likely & 126 & 34.8 \\
\cline { 2 - 4 } & Very likely & 123 & 34.0 \\
\hline \multirow{2}{*}{ Home Language } & Afrikaans & 6 & 1.7 \\
\cline { 2 - 4 } & English & 99 & 27.3 \\
\cline { 2 - 4 } & Indigenous South African or African language & 250 & 69.1 \\
\cline { 2 - 4 } & Other (Chinese, French, etc.) & 7 & 1.9 \\
\hline
\end{tabular}

competence (relating students' attitudes about their intellectual knowledge and skills when applied to statistics); value (unfolding students' attitudes about the usefulness, relevance, and worth of statistics in personal and professional life); and difficulty (telling students' state of mind about the difficulty of statistics as a subject). Later, Schau (2003) extended the original form to a 36-item version (SATS-36) including two additional factors: interest (describing students' level of individual interest in statistics); and effort (clarifying the amount of work the student expends to learn statistics). The responses for the SATS-36 survey were measured on a seven-point Likert scale (1 $=$ strongly disagree, $4=$ neither disagree nor agree, 7 = strongly agree), where higher scores correspond to a more positive attitude and lower scores to a more negative attitude. Together with the SATS-36 questionnaire, we included a few additional items to explore participants' biographical data and former mathematics achievement in Grade 12.

\section{Participants}

\section{Pre-test sample}

Six hundred undergraduate statistics students, studying on a full-time basis at the University of Johannesburg (UJ), took part in the pre-test investigation. A convenient sampling method was utilised and participants completed the survey online via the UJ student portal during the first term of the academic year in 2017. The participants consisted of 130 first-year students from the Faculty of Science (39 female, 91 male, $\mathrm{N}=169$ ); 196 third-year students from the Faculty of Engineering (42 female, 154 male, $N=267$ ); and 274 first-year students from the Faculty of Management (155 female, 119 male, $\mathrm{N}=483$ ). Table 1 displays descriptive statistics of the pre-test sample.

\section{Post-test sample}

The participants (362) in the post-test, sampled similar to the pre-test, were all full-time UJ students. The collection of data (comparable with the pre-test) was during the last term of the 2017 academic year. These participants consisted of 80 first-year students from the Faculty of Science (26 female, 54 male, $\mathrm{N}=132$ ) and 282 first-year students from the Faculty of Management (156 female, 126 male, $\mathrm{N}=400$ ). Table 2 shows descriptive statistics for the post-test sample. From Table 1 (pre-test statistics), approximately $26 \%$ of participants were not at all likely to choose statistics to be part of their degree if the choice had been theirs and only $19 \%$ of participants indicated English (the medium of instruction at UJ) as their home language. From Table 2 (post-test statistics), even more participants $(31 \%)$ indicated they were not likely to choose the subject by choice and $27 \%$ confirmed English as their home language.

We viewed both aspects, the eagerness of choosing statistics as a subject and home language versus language of instruction, as relevant for this study and, in general, to inform statistics pedagogy. 
Table 3. Example item per factor in SATS-36

\begin{tabular}{ll}
\hline Factor & Example Items \\
\hline Affect ( 6 items) & 1. I will like statistics \\
\hline Cognitive Competence $(6$ items) & 31. I can learn statistics \\
\hline Value $(9$ items) & 10. Statistical skills will make me more employable \\
\hline Difficulty $(7$ items) & $34 .{ }^{*}$ Statistics is highly technical \\
\hline Interest $(4$ items) & 20. I am interested in using statistics \\
\hline Effort (4 items) & 2. I plan to/did work hard in my statistics course \\
\hline${ }^{*}$ negatively worded items are reverse coded to assure that high scores represent a positive attitude (i.e., 1 becomes 7,2 becomes 6.$)$
\end{tabular}

Table 4. Cronbach alpha levels per factor

\begin{tabular}{|c|c|c|c|}
\hline \multirow{2}{*}{ Factor } & \multirow{2}{*}{ Faculty } & \multicolumn{2}{|c|}{ Cronbach alpha } \\
\hline & & Pre & Post \\
\hline \multirow{2}{*}{ Affect } & Science & 0.8 & 0.9 \\
\hline & Management & 0.8 & 0.9 \\
\hline \multirow{2}{*}{ Cognitive Competence } & Science & 0.6 & 0.7 \\
\hline & Management & 0.8 & 0.8 \\
\hline \multirow{2}{*}{ Value } & Science & 0.7 & 0.8 \\
\hline & Management & 0.8 & 0.9 \\
\hline \multirow{2}{*}{ Difficulty } & Science & 0.5 & 0.5 \\
\hline & Management & 0.6 & 0.5 \\
\hline \multirow{2}{*}{ Interest } & Science & 0.8 & 0.8 \\
\hline & Management & 0.9 & 0.9 \\
\hline \multirow{2}{*}{ Effort } & Science & 0.8 & 0.8 \\
\hline & Management & 0.7 & 0.7 \\
\hline
\end{tabular}

\section{Ethical Measures, Validity and Reliability}

Regarding ethical measures, on both data-collection occasions, participants were informed about the purpose of the inquiry; they intentionally participated, and their confidentiality and anonymity were ensured. The validity of SATS-36 has been studied in literature reports, locally and internationally (Coetzee \& van der Merwe, 2010; Nolan et al., 2012; Vanhoof et al., 2011).

The instrument was confirmed to be a valid measure of students' attitude towards statistics as it covers the particular domain. However, much debate has taken place on whether six or four factors should be included in the measure. Reasons were raised to maintain the six-factor model, such as its validation in several studies and allowing researchers to compare recent findings with former studies. Furthermore, Vanhoof et al. (2011) thoroughly investigated the structure of the SATS-36 survey, by confirmatory factor analysis - they confirmed that the sixfactor model outperformed the four-factor model in their investigation. Table 3 displays an example item per factor.

Table 4 displays the Cronbach alpha levels per factor to confirm internal consistency. All factors (affect, cognitive competence, value, difficulty, interest and effort) showed acceptable levels consistent with former studies (Coetzee \& van der Merwe, 2010; Nolan et al., 2012). Moreover, the difficulty factor showed a low (although acceptable) level of internal consistency (Cronbach alpha $=0.5$ to 0.6). Vanhoof et al. (2011) pointed out that this could largely be due to two of the items (item 22 and item 36) in the difficulty factor, which asks about most people's attitudes regarding the difficulty of statistics, rather than the students' own attitude. Furthermore, Vanhoof et al. (2011) suggested that removing the two items from the analysis could increase the level of internal consistency. However, we decided to maintain the two items in the analysis so that it is more comparable with other studies.

\section{DATA ANALYSIS AND FINDINGS}

The purpose of the study is to explore the initial attitudinal differences of students between mainstream and service course and to track these from the beginning to the end of a course. Data were obtained from students enrolled in the Faculties of Management, Engineering and Science and analysed by the Statistical Package of the Social Sciences (SPSS version 24). From Figure 1 (displaying pre-test data), attitudes in terms of affect, cognitive competence, value, effort and interest can be seen as more positive in nature, whereas difficulty seems to be more neutral. Surprisingly, the effort factor falls near the top of the seven-point Likert scale - which is unlikely to become more positive in post-test results. Van Appel and Durandt (2017) compared these pre-test attitudinal scores. They found significant differences in attitudes towards statistics and between genders. Four factors (affect, difficulty, interest and effort) contributed towards the attitudinal differences between courses and three factors (affect, 


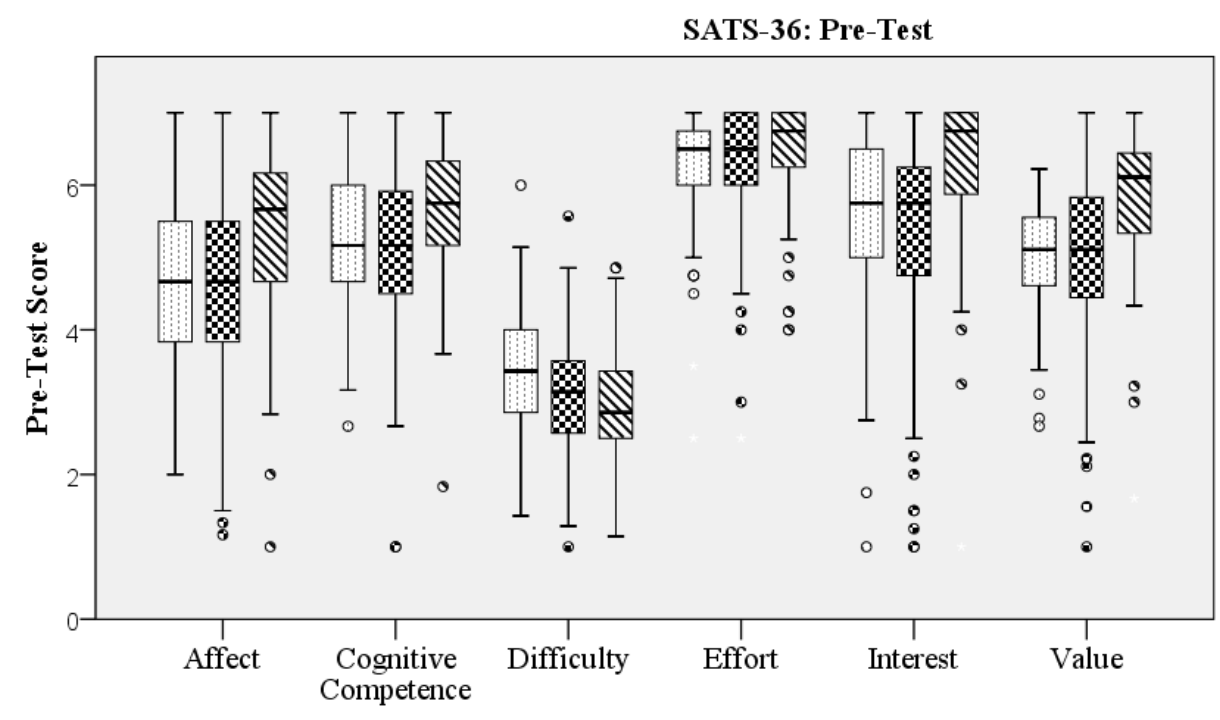

Course

Faculty of Engineering QFaculty of Managemen $\mathbb{N}$ Faculty of Science

Pre-Test Factor

Figure 1. Boxplots illustrating pre-test attitudinal scores

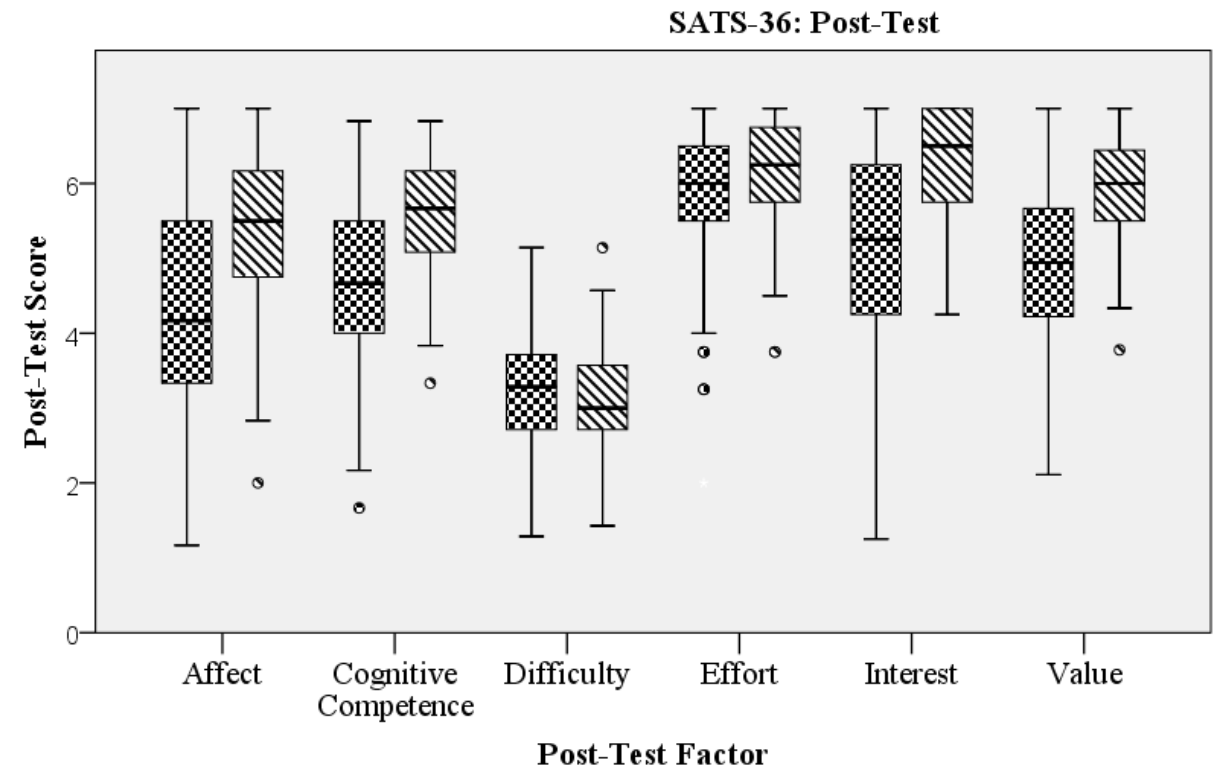

Course

QFaculty of Managemen NFaculty of Science

Figure 2. Boxplots illustrating post-test attitudinal scores

difficulty and effort) contributed towards attitudinal differences in gender. More specifically, they established that students in service courses enjoyed statistics less than students in the mainstream courses, they experienced the subject as more difficult, had lower interest in learning the content, and needed to put in more effort to learn statistics. Similarly, female students enjoyed statistics less, found the subject more difficult, and needed to put in more effort to learn statistics than their male counterparts did.

In Figure 2 (displaying post-test data), all factors are shown more positive in nature, except for the difficulty factor (similar to pre-test data).

To investigate the attitudinal difference towards statistics between the service and mainstream modules for the post-test data (the width of the gap between service and mainstream modules), we carried out multiple two-sample independent Mann-Whitney $U$ tests. This is a non-parametric hypothesis test used to determine significant differences in a scale or ordinal variable. Table 5 displays the Mann-Whitney U test results. 
EURASIA J Math Sci and Tech Ed

Table 5. Differences in attitudes (pre-test versus post-test)

\begin{tabular}{|c|c|c|c|c|}
\hline Factor & Test Variables & Mean Rank & Mann-Whitney U & $p$-value (2-tailed) \\
\hline \multicolumn{5}{|c|}{ Mainstream vs service module } \\
\hline \multirow[t]{2}{*}{ Affect } & Faculty of Science & 243.55 & 6316 & 0 \\
\hline & Faculty of Management & 163.9 & & \\
\hline \multirow{2}{*}{$\begin{array}{c}\text { Cognitive } \\
\text { Competence } \\
\end{array}$} & Faculty of Science & 246.63 & 6070 & 0 \\
\hline & Faculty of Management & 163.02 & & \\
\hline \multirow[t]{2}{*}{ Value } & Faculty of Science & 266.29 & 4497 & 0 \\
\hline & Faculty of Management & 157.45 & & \\
\hline \multirow[t]{2}{*}{ Difficulty } & Faculty of Science & 169.07 & 10285 & 0.228 \\
\hline & Faculty of Management & 185.03 & & \\
\hline \multirow[t]{2}{*}{ Interest } & Faculty of Science & 258.85 & 5092 & 0 \\
\hline & Faculty of Management & 159.56 & & \\
\hline \multirow[t]{2}{*}{ Effort } & Faculty of Science & 204.47 & 9442.5 & 0.025 \\
\hline & Faculty of Management & 174.98 & & \\
\hline & & Gender & & \\
\hline \multirow{2}{*}{ Affect } & Female & 165.03 & 13383 & 0.003 \\
\hline & Male & 198.15 & & \\
\hline \multirow{2}{*}{$\begin{array}{c}\text { Cognitive } \\
\text { Competence }\end{array}$} & Female & 171.22 & 14509 & 0.060 \\
\hline & Male & 191.89 & & \\
\hline \multirow[t]{2}{*}{ Value } & Female & 174.48 & 15102 & 0.199 \\
\hline & Male & 188.6 & & \\
\hline \multirow[t]{2}{*}{ Difficulty } & Female & 179.51 & 16017 & 0.715 \\
\hline & Male & 183.52 & & \\
\hline \multirow[t]{2}{*}{ Interest } & Female & 169.15 & 14133 & 0.024 \\
\hline & Male & 193.98 & & \\
\hline \multirow[t]{2}{*}{ Effort } & Female & 192.48 & 14381 & 0.043 \\
\hline & Male & 170.39 & & \\
\hline
\end{tabular}

Firstly, the findings indicated that five factors (affect, cognitive competence, value, interest and effort) showed significant differences ( $p$-value $<0.05$ ) in attitudes towards statistics between mainstream and service modules in the post-test. More specifically, we found that students' attitudes in mainstream statistics modules were significantly higher in affect, cognitive competence, value, interest and effort, compared with students in service modules. This shows that there was no visible improvement in closing the attitudinal gap between mainstream and service modules in statistics, over the period in this study. Secondly, we found significant differences in affect, interest and effort between genders. When compared to the pre-test results (reported in Van Appel \& Durandt, 2017) we realised that female students did not find statistics more difficult anymore, but showed less interest in the course. However, a thorough investigation into this will be left for further research.

To investigate, within each faculty, the difference in participants' attitudinal scores towards statistics between the pre-test and post-test, our sample consisted only of participants that answered both these surveys - 161 students from the Faculty of Management and 54 students from the Faculty of Science. Figure 3 displays participants' responses on one of the added questions (apart from SATS-36, view the discussion on 'research instrument'), 'If the choice had been yours, how likely is it that you would have chosen to take statistics'.

Somewhat disturbing, after two semesters of statistics, there was no visual increase in the likelihood of students in the Faculty of Management (service module) choosing the subject by choice. Keeping in mind the requirement for statistical competence in many professions, statistic educators could reflect on these results when considering methods of instruction.

Table 6 displays descriptive statistics regarding participants' attitudes towards statistics for both the pre-test and post-test. The mean, median and modal scores (out of 7) for each factor indicated a more positive attitude towards statistics. Difficulty seemed to be the most negative prevailing attitude, with a modal score of 3 for students in the Faculty of Science and 3.1 for students in the Faculty of Management. To comprehend the development of participants' attitude towards statistics, we compared the initial attitude (pre-test) with the ending attitude (posttest). 


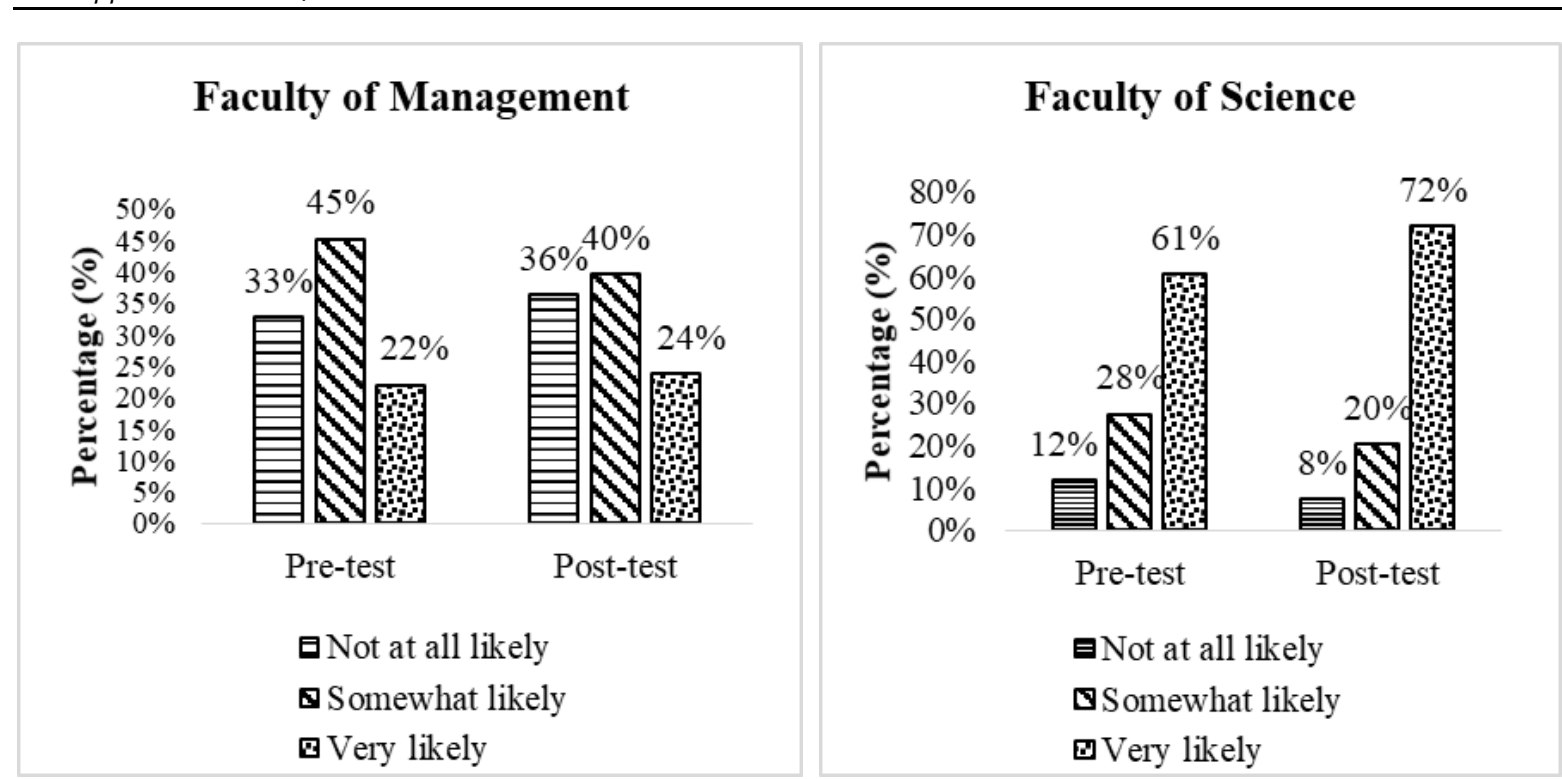

Figure 3. Findings displaying participants' likelihood to choose statistics as a subject

Table 6. Descriptive statistics for pre-test and post-test data

\begin{tabular}{|c|c|c|c|c|c|c|c|c|c|}
\hline \multirow{2}{*}{ Factor } & \multirow{2}{*}{ Faculty } & \multicolumn{2}{|c|}{ Mean } & \multicolumn{2}{|c|}{ Median } & \multicolumn{2}{|c|}{ Mode } & \multicolumn{2}{|c|}{ Std. Dev. } \\
\hline & & Pre & Post & Pre & Post & Pre & Post & Pre & Post \\
\hline \multirow{2}{*}{ Affect } & Science & 5.5 & 5.3 & 5.6 & 5.5 & 6.5 & 5.8 & 1.1 & 1.2 \\
\hline & Management & 4.7 & 4.5 & 4.7 & 4.5 & 4.0 & 4.7 & 1.1 & 1.3 \\
\hline \multirow{2}{*}{ Cognitive Competence } & Science & 5.8 & 5.5 & 5.8 & 5.6 & 5.7 & 5.8 & 0.7 & 0.8 \\
\hline & Management & 5.2 & 4.8 & 5.2 & 4.8 & 5.2 & 4.0 & 0.9 & 1.0 \\
\hline \multirow{2}{*}{ Value } & Science & 5.9 & 6.0 & 6.1 & 6.1 & 6.1 & 6.7 & 0.7 & 0.7 \\
\hline & Management & 5.0 & 4.9 & 5.0 & 5.0 & 5.6 & 5.7 & 1.0 & 1.0 \\
\hline \multirow{2}{*}{ Difficulty } & Science & 3.0 & 3.0 & 2.9 & 3.0 & 3.1 & 2.7 & 0.7 & 0.6 \\
\hline & Management & 3.1 & 3.2 & 3.1 & 3.3 & 3.0 & 3.9 & 0.7 & 0.7 \\
\hline \multirow{2}{*}{ Interest } & Science & 6.3 & 6.3 & 6.8 & 6.5 & 7.0 & 7.0 & 0.8 & 0.8 \\
\hline & Management & 5.4 & 5.1 & 5.5 & 5.3 & 6.0 & 6.5 & 1.3 & 1.4 \\
\hline \multirow{2}{*}{ Effort } & Science & 6.7 & 6.2 & 6.8 & 6.3 & 7.0 & 6.3 & 0.4 & 0.8 \\
\hline & Management & 6.4 & 6.0 & 6.8 & 6.3 & 7.0 & 6.5 & 0.6 & 0.8 \\
\hline
\end{tabular}

A multiple paired two-sample Wilcoxon Signed Rank tests (displayed in Table 7 and Table 8) were applicable. The Wilcoxon signed-rank test is a non-parametric statistical hypothesis test to compare two related samples. In Table 7, significant differences $(p$-value $<0.05$ ) were found between the pre-test and post-test scores in the Faculty of Management with regarding to the factors affect, cognitive competence, interest and effort, at a 95\% confidence level. More specifically, the ranks indicated all six factors have significantly decreased in attitude in the post-test. Similarly, we found statistically significant differences $(p$-value $<0.05)$ between the post-test and the pre-test scores in the Faculty of Science for cognitive competence and effort, at a 95\% confidence level. The ranks, displayed in Table 8 , indicated these two factors have significantly decreased in attitude in the post-test. For both faculties there has been a decrease is cognitive competence and effort in the post-test, which indicated participants' attitudes about their intellectual knowledge and skills when applied to statistics decreased. From the findings, we could conclude participants' confidence in their skills and ability to learn statistics has decreased significantly. Furthermore, participants indicated that they spent less time learning statistics, shown by the significant decrease in post-test effort. Students in the Faculty of Management showed a significant lower affect and interest, indicating they enjoyed statistics less and found fewer interests in the subject. 
EURASIA J Math Sci and Tech Ed

Table 7. Wilcoxon Signed Ranks - Faculty of Management

\begin{tabular}{|c|c|c|c|c|c|c|}
\hline Factor & Ranks & $\mathbf{N}$ & Mean Rank & Sum of Ranks & $\mathbf{Z}$ & $p$-value (2-tailed) \\
\hline \multirow{3}{*}{ Affect } & Negative & $86^{a}$ & 80.85 & 6953 & -2.76 & 0.006 \\
\hline & Positive & $62^{\mathrm{b}}$ & 65.69 & 4073 & & \\
\hline & Ties & $13^{c}$ & & & & \\
\hline \multirow{3}{*}{ Cognitive Competence } & Negative & $97^{a}$ & 83.13 & 8063.5 & -4.328 & 0 \\
\hline & Positive & $54^{\mathrm{b}}$ & 63.19 & 3412.5 & & \\
\hline & Ties & $10^{c}$ & & & & \\
\hline \multirow{3}{*}{ Value } & Negative & $86^{a}$ & 77.56 & 6670.5 & -1.734 & 0.083 \\
\hline & Positive & $65^{\mathrm{b}}$ & 73.93 & 4805.5 & & \\
\hline & Ties & $10^{c}$ & & & & \\
\hline \multirow{3}{*}{ Difficulty } & Negative & $67^{a}$ & 70.28 & 4708.5 & -0.887 & 0.375 \\
\hline & Positive & $76^{\mathrm{b}}$ & 73.52 & 5587.5 & & \\
\hline & Ties & $18^{c}$ & & & & \\
\hline \multirow{3}{*}{ Interest } & Negative & $92^{a}$ & 74.27 & 6833 & -3.773 & 0 \\
\hline & Positive & $49^{b}$ & 64.86 & 3178 & & \\
\hline & Ties & $20^{c}$ & & & & \\
\hline \multirow{3}{*}{ Effort } & Negative & $106^{a}$ & 74.74 & 7922.5 & -6.473 & 0 \\
\hline & Positive & $33^{b}$ & 54.77 & 1807.5 & & \\
\hline & Ties & $22^{c}$ & & & & \\
\hline
\end{tabular}

a. Post_Factor $<$ Pre_Factor; b. Post_Factor $>$ Pre_Factor; $c$. Post_Factor $=$ Pre_Factor

Table 8. Wilcoxon Signed Ranks - Faculty of Science

\begin{tabular}{|c|c|c|c|c|c|c|}
\hline Factor & Ranks & $\mathbf{N}$ & Mean Rank & Sum of Ranks & $\mathbf{Z}$ & $p$-value (2-tailed) \\
\hline \multirow{3}{*}{ Affect } & Negative & $28^{a}$ & 24.23 & 678.5 & -1.215 & 0.225 \\
\hline & Positive & $19^{\mathrm{b}}$ & 23.66 & 449.5 & & \\
\hline & Ties & $7^{c}$ & & & & \\
\hline \multirow{3}{*}{ Cognitive Competence } & Negative & $31^{a}$ & 26.68 & 827 & -2.458 & 0.014 \\
\hline & Positive & $17^{\mathrm{b}}$ & 20.53 & 349 & & \\
\hline & Ties & $6^{c}$ & & & & \\
\hline \multirow{3}{*}{ Value } & Negative & $18^{a}$ & 23.14 & 416.5 & -1.143 & 0.253 \\
\hline & Positive & $27^{\mathrm{b}}$ & 22.91 & 618.5 & & \\
\hline & Ties & $9^{c}$ & & & & \\
\hline \multirow{3}{*}{ Difficulty } & Negative & $24^{a}$ & 25.73 & 617.5 & -0.05 & 0.96 \\
\hline & Positive & $25^{\mathrm{b}}$ & 24.3 & 607.5 & & \\
\hline & Ties & $5^{c}$ & & & & \\
\hline \multirow{3}{*}{ Interest } & Negative & $15^{a}$ & 17.37 & 260.5 & -0.248 & 0.804 \\
\hline & Positive & $16^{\mathrm{b}}$ & 14.72 & 235.5 & & \\
\hline & Ties & $23^{c}$ & & & & \\
\hline \multirow{3}{*}{ Effort } & Negative & $37^{\mathrm{a}}$ & 21.51 & 796 & -4.338 & 0 \\
\hline & Positive & $5^{b}$ & 21.4 & 107 & & \\
\hline & Ties & $12^{\mathrm{c}}$ & & & & \\
\hline
\end{tabular}

a. Post_Factor $<$ Pre_Factor; b. Post_Factor $>$ Pre_Factor; c. Post_Factor $=$ Pre_Factor

\section{CONCLUSION}

The professional development of students at tertiary level over a variety of disciplines requires statistical competencies. Statistics students (more so in developing countries) generally display lower attitudinal scores towards the subject, lack fundamental mathematical knowledge and perform unsatisfactorily in statistics courses (Coetzee \& van der Merwe, 2010; Juan \& Visser, 2017; Rylands \& Coady, 2009; Spaull, 2013; Van Appel \& Durandt, 2017). Students learn statistics through active involvement and participation in the learning activities and by fostering, a more positive disposition towards the subject and former studies almost pleaded for innovative teaching and learning strategies (Garfield \& Ben-Zvi, 2007; Jose, 2017).

In this study, we compared the attitudes of students towards statistics in the Faculty of Science (students enrolling for statistics as a mainstream course) with the attitudes of students in the Faculties of Management and Engineering (students enrolling for statistics as a service module course). We attempted to answer the two research questions: 
- What are the initial differences between the attitudes of students in service and mainstream courses toward statistics?

- Are their changes in the attitudinal scores of statistics students (between mainstream and service courses) from the beginning (labelled as the pre-test) to the end of the particular module (labelled as the post-test)?

Aligned with the theoretical framework on "Statistical Reasoning, Thinking, and Literacy" from Garfield and Ben-Zvi (2007, p. 380) and the strong relation between learning statistics and fostering a positive attitude toward the discipline, the researchers conducted this investigation. Quantitative data were collected on two occasions via the valid and reliable SATS-36 instrument. Findings revealed significant differences in attitudes of students between service and mainstream courses towards statistics and between genders. Likewise, significant differences in attitudes where detected between the pre-test and post-test scores. The finding revealed, on average, students' attitudes towards statistics did not change over two semesters or become more negative over time. These findings compare with other studies (for example, Schau, 2003; Sizemore \& Lewandowski, 2009).

Although this South African study accentuates that statistics students in service modules reveal lower attitudinal scores towards statistics than students in mainstream courses, all students find the subject rather difficult and they are less likely to choose statistics by choice. It is therefore crucial for statistics educators to consider the teaching and learning practices per discipline, but also across different disciplines. Furthermore, educators should investigate a broad spectrum of interventions to scaffold course content to address the difficulty factor in statistics courses. Keeping students involved and motivated throughout a statistics course places another responsibility on the educator and requires a certain amount of innovation. Ideally, statistics students in different faculties should be engaged in a well-planned set of activities, focusing on their particular professional development, aimed at strengthening their competencies and gradually improving their attitudes towards the subject. This is left for further investigation.

\section{ACKNOWLEDGEMENTS}

We gratefully acknowledge the valuable contribution of Carmel McNaught in the preparation of this paper and Candace Schau for granting consent for SATS-36 in 2017.

\section{REFERENCES}

Bakker, A., \& Gravemeijer, K. P. E. (2004). Learning to reason about distributions. In D. Ben-Zvi \& J. Garfield (Eds.), The challenge of developing statistical literacy, reasoning, and thinking, pp. 147-168. Dordrecht: Kluwer Academic. https:/ / doi.org/10.1007/1-4020-2278-6_7

Chick, H. L., \& Watson, J. M. (2002). Collaborative influences on emergent statistical thinking - a case study. Journal of Mathematical Behaviour, 21, 371-400. https:/ / doi.org/10.1016/S0732-3123(02)00135-9

Coetzee, S. \& van der Merwe, P. (2010). Industrial psychology students' attitudes towards statistics. SA Journal of Industrial Psychology / SA Tydskrif vir Bedryfsielkunde, 36(1), 1-8. https:/ / doi.org/10.4102/ sajip.v36i1.843

Creswell, J. W. (2013). Research design: Qualitative, quantitative, and mixed methods approaches. Thousand Oaks, CA: Sage publications.

Department of Basic Education. (2011). Curriculum and Assessment Policy Statement (CAPS) Grades 10-12 Mathematics. South Africa. Retrieved from http:/ / www.education.gov.za/

Garfield, J. (1995). How students learn statistics. International Statistics Review, 63, 25-34. https:/ / doi.org/10.2307/1403775

Garfield, J., \& Ben-Zvi, D. (2007). How students learn statistics revisited: A current review of research on teaching and learning statistics. International Statistical Review, 75(3), 372-396. https://doi.org/10.1111/j.17515823.2007.00029.x

Garfield, J., \& Chance, B. (2000). Assessment in statistics education: Issues and challenges. Mathematical Thinking Learning, 2, 99-125. https:/ / doi.org/10.1207/S15327833MTL0202_5

Jose, P. E. (2017). Observations about how we learn about methodology and statistics. Monographs of the Society for Research in Child Development, 82(2), 140-151. https:/ / doi.org/10.1111/mono.12303

Juan, A., \& Visser, M. (2017). Home and school environmental determinants of science achievement of South African students. South African Journal of Education, 37(1). 1-10. https:/ / doi.org/10.15700/ saje.v37n1a1292

Mills, J.D. (2004). Students' attitudes towards statistics: Implications for the future. College Student Journal, 38, 349361.

$10 / 11$ 
Nolan, M. M., Beran, T., \& Hecker, K. G. (2012). Surveys assessing students' attitudes toward statistics: a systematic review of validity and reliability. Statistics Education Research Journal, 11(2), 103-123. Available from http://www.stat.auckland.ac.nz/serj

Pfannkuch, M. (2005). Probability and statistical inference: How can teachers enable learners to make the connection? In G. A. Jones (Ed.), Exploring probability in school: Challenges for teaching and learning, pp. 267294. New York: Springer. https:/ / doi.org/10.1007/0-387-24530-8_12

Phillips, D. C., \& Burbules, N. C. (2000). Postpositivism and educational research. Lanham, MD: Rowman \& Littlefield.

Rylands, L. J., \& Coady, C. (2009). Performance of students with weak mathematics in first-year mathematics and science. International Journal of Mathematical Education in Science and Technology, 40(6), 741-753. https:/ / doi.org/10.1080/0020-7390902914130

Schau, C. (2003). Students' attitudes: The 'other' important outcomes in statistics education. Joint Statistical Meetings, San Francisco.

Schau, C., Stevens, J., Dauphinee, T.L., \& Del Vecchio, A. (1995). The development and validation of the Survey of Attitudes toward Statistics. Educational and Psychological Measurement, 55, 868-875. https://doi.org/10.1177/0013164495055005022

Sizemore, O. J., \& Lewandowski, G. W. (2009). Learning might not equal liking: Research methods course changes knowledge but not attitudes. Teaching of Psychology, 36(2), 90-95. https:/ / doi.org/10.1080/00986280902739727

Spaull, N. (2013). South Africa's education crisis: The quality of education in South Africa. Johannesburg: Centre for Development and Enterprise, pp. 1994-2011.

Sulieman, H. (2015). Students' conception of statistics: an exploration of attitudes across majors. International Research in Education, 3(2), 158-172. https:/ / doi.org/10.5296/ire.v3i2.7622

Van Appel, V., \& Durandt, R. (2017). Investigating the attitudinal differences of students in service and mainstream courses towards statistics. Proceedings: Towards Effective Teaching and Meaningful Learning in Mathematics, Science and Technology Education, (pp. 199-205). 23-26 October 2017, Mopani Camp, Kruger National Park, South Africa.

Vanhoof, S., Kuppens, S., Sotos, A. E. C., Verschaffel, L., \& Onghena, P. (2011). Measuring statistics attitudes: Structure of the Survey of Attitudes toward Statistics (SATS-36). Statistics Education Research Journal, 10(1), 35-51. Retrieved from http://www.stat.auckland.ac.nz/ iase/serj/SERJ10\%281\%29_Vanhoof.pdf

Yousef, D. A. (2017). Factors influencing academic performance in quantitative courses among undergraduate business students of a public higher education institution. Journal of International Education in Business, 10(1), 12-30. https:/ / doi.org/10.1108/JIEB-07-2016-0016

\section{http://www.ejmste.com}

